\title{
Antibiofilm of a Tooth Paste on Cariogenic Bacteria
}

\author{
Rafit Jasim Aladool, Ghada Younis Abdul-Rahman, \\ ${ }^{1}$ Department of Oral Surgery, College of Dentistry, Mosul University, Iraq \\ ${ }^{2}$ Department of Dental Basic Sciences, College of Dentistry, Mosul University, Iraq \\ *Corresponding author: ghadakahwaji@gmail.com
}

\begin{abstract}
Caries is an infectious diseases of the oral cavity in which oral biofilms play a causative role. Moreover, oral biofilms are widely studied as model systems for bacterial adhesion, biofilm development, and drugs acting on biofilm to, due to their widespread presence and accessibility. The aim of the present in vitro study was to investigate the efficacy of specific fluoridated toothpaste on the biofilms formed by the test microorganisms (Streptococcus mutans, Facklamia homins and Streptococcus saliviurus). The colonizations of the three test bacteria on four surfaces (two natural; permenant and deciduous tooth surfaces and two artificial ;composite and amalgam filling surfaces) were observed with scanning electron microscopy (SEM).SEM detected the anti-biofilm effects on the same four surfaces medicated with a tooth paste. Results: The used tooth paste declined the formed biofilms on four surfaces efficiently. The natural tooth surfaces responded in same manner to the tooth paste while composite responded more efficiently than amlagam surfaces. Conclusions: Flourdated toothpaste $(0.454 \%)$ effectively can remove formed biofilms of the three test bacteria on natural surfaces and composite filling surfaces. It removed formed biofilm on amalgam surfaces but not as from other three surfaces.
\end{abstract}

Keywords: Toothpaste, Flouride, Biofilm, Streptococcus mutans, Facklamia homins, Streptococcus saliviurus, Scanning electron microscope, permanent and deciduous tooth , composite and amalgam filling

Cite This Article: Rafit Jasim Aladool, and Ghada Younis Abdul-Rahman, "Antibiofilm of a Tooth Paste on Cariogenic Bacteria." International Journal of Dental Sciences and Research, vol. 6, no. 5 (2018): 110-117. doi: 10.12691/ijdsr-6-5-1.

\section{Introduction}

More than 700 unique bacterial species have been detected in the oral cavity. [1] Most of the them are harmless bacteria, but some have the ability to cause damage. [2] Dental caries is an infectious, multi-factorial disease caused by bacteria which aggregated in pathogenic biofilm. [3,4] A biofilm can be defined as a complex bacterial structure formed on a solid surface that provides protections to related bacteria from the host's immune defense and from antimicrobial agents. [5] Maintenance of good oral hygiene is the cornerstone for prevention of many dental diseases. [6] Toothpaste is considered as one of the most important means used to promote oral hygiene [7]. It is classified as drugs not cosmetics as it contains an ingredient to achieve the desired pharmacological effect. [8] The efficiency of any toothpaste in part, lies on its ability to remove pathogenic oral micro-flora [9] or by decreasing the accumulation of oral biofilms which is responsible for development of dental caries. Fluoride which is the mostly widely applied in tooth paste, has been the key of caries prevention for over many years [10,11].

\section{Methods}

\section{Isolation and Identification of Oral Bacteria}

Saliva samples were taken from several patients with dental caries at college of dentistry/University of Mousl-Iraq. After suitable mixing, dilution and inoculation on the three selective media, Mitis Salivirus Bactracin agar (Himedia, India), Rogosa SL agar (Himedia, India) and m Enterococcus agar (Himedia, India), colonies from each media were checked by automated microbial identification instrument (Vitek 2, BioMerieux, France) at Vin medical centre (Douhok, Iraq). Only three bacteria were selected. They were Streptococcus mutans, Facklamia hominis and Streptococcus salivarus [12].

\section{Biofilm Formation Assay}

In this experiment, attachment surfaces were :-

A-Natural surfaces: - which included both permanent and deciduous teeth surfaces.

Freshly extracted sound permanent and deciduous molars were manually scaled to remove calculus and surface-adhered debris. Sterilization was done by autoclaving with steam1psi, typically at $121^{\circ} \mathrm{C}$ for a minimum of 15 minutes. A perpendicular cuts to long axis of buccal surfaces of permanent and deciduous teeth were made. At end, enamel slabs of $5 \mathrm{~mm} \times 5 \mathrm{~mm}$ measurements were obtained $[12,13]$.

B. Artificial surfaces: - which included amalgam and composite fillings surfaces.

Amalgam capsules (high silver 69\%, Ventura, Spain) were mixed with amalgam mixer according to manufacture instructions, allowed to set in $5 \mathrm{~mm} \times 5 \mathrm{~mm}$ measurements mold and polished with polishing paste. Composite slabs were made by putting the composite material (Estelite alpha, Tokuyama, Japan) in $5 \mathrm{~mm} \times 5 \mathrm{~mm}$ measurements transparent mold, light curring according to manufacture instructions (20 sec) and polishing with polishing paste. 


\subsection{Biofilm Formation Procedure}

A-The three identified bacterial strains( Streptococcus mutans, Facklamia hominis and Streptococcus salivarus) were cultivated overnight in $20 \mathrm{ml}$ sterile BHI broth at $37^{\circ} \mathrm{C}$ anaerobically for the first strain and aerobically for the others and their growth were compared visually to McFarland Standerd No. 2 which equaled to $6 \times 10^{8}$ bacteria cells.

B-The four tested surfaces(natural and artificial) were separately put in new $20 \mathrm{ml}$ BHI broth and sterilized at $121^{\circ} \mathrm{C}$ for $15 \mathrm{~min}$ to insure sterile broth and surfaces.

C-One tenth milliliter from the two identified bacterial BHI broths (Streptococcus mutans with Facklamia hominis and Streptococcus salivarus with Facklamia hominis) were put aseptically in the sterile BHI broth contained the tested surfaces and incubated according to the bacterial cultural requirements.

D-Each tested surfaces was washed with phosphate buffer saline( PBS), fixed in 2\% glutteraldehyde for $1 \mathrm{~h}$ at $37^{\circ} \mathrm{C}$ then washed again with PBS twice times and left to dry at room temperature [14].

E-Samples were sent for examination using scanning electron microscope in Ministry of Sciences and Technology-Baghdad/Iraq.

\subsection{Anti-Biofilm Formation Assay}

The same procedure in 2.1 was repeated except fourth step was done as follow:-Each tested surfaces was washed with PBS and before fixation with in $2 \%$ glutteraldehyde, $0.1 \mathrm{ml}$ of tested tooth paste (Sensodyne repair and protect, USA contain stannous fluoride $0.454 \%$ as active ingredient) covered the entire tested surface for $30 \mathrm{~min}$ at $37^{\circ} \mathrm{C}$, washed with PBS, fixed in $2 \%$ glutteraldehyde for $1 \mathrm{~h}$ at $37^{\circ} \mathrm{C}$ then washed again with PBS twice times and left to dry at room temperature sent for using scan electron microscope [15].

\section{Results}

Figure 1, revealed the effects of test tooth paste on biofilm of single test bacteria (Streptococcus mutans) to investigate the bacterial cellular changes individually. Scanning electron micrographs showed the biofilms of

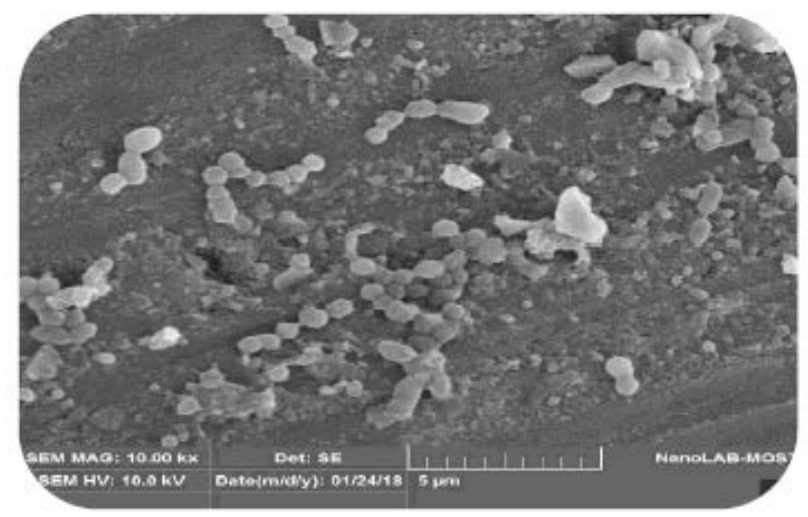

- A.Biofilm x10.00 two test bacteria (Streptococcus mutans with Facklamia hominis and Streptococcus salivarus with Facklamia hominis) on the permentant tooth surfaces, deciduous tooth surfaces, amalgam filling surfaces and composite filling surfaces before and after application of flourdated tooth paste, respectively(Figure 2 - Figure 5).

\section{Discussion}

The ordinary oral hygiene method of tooth brushing is, by itself, usually inadequate over a long period to provide an acceptable level of plaque control. Consequently, the addition of chemical agents with anti-plaque or antimicrobial activity into dental products has been used as a potential prophylactic method of reducing plaque-mediated disease $[16,17]$.

Today's toothpastes have two purposes: to clean the tooth surface and to add a therapeutic effect. The therapeutic effect may either an antiplaque or anti-inflammatory [18].

Fluoride is considered to be an efficient anticaries agent because of the several supposed mechanisms of action; inhibition of the demineralization, facilitation of the remineralization and suppression of the bacterial metabolism (i.e. antibacterial effect) - by binding and inactivating many of the enzymes involved in different bacterial metabolic pathways.An indirect effect on the biofilm development can be also done by inhibiting the growth of oral bacteria [19].

Fluoride at $0.05 \%$, is considered as a type of antimicrobials used clinically in toothpaste and mouthwashes to decrease plaques and prevent caries. [20] Watson et al, 2005, founded that mean biomass fluoride concentrations in biofilms exposed to flouride for $30 \mathrm{~min}$ were significantly higher than biomass fluoride concentrations (30 sec, $120 \mathrm{sec}, 30 \mathrm{~min}$ ) [21].

In Figure 1, it showed the effects of test tooth paste on mono biofilm of Streptococcus mutans. The application of fluoridated tooth paste not only remove the formed biofilm but cause morphological changes of the bacterial cells.

The bacterial cocci appeared elongated, swollen, scattered and change in their orientations .These changes were due to the pharmacological effects of fluoride. These results came with the same results reached by Abd El-Baky R. M (2012) who treated S. aureus with ciprofloxacin-N-acetylcystein [14].

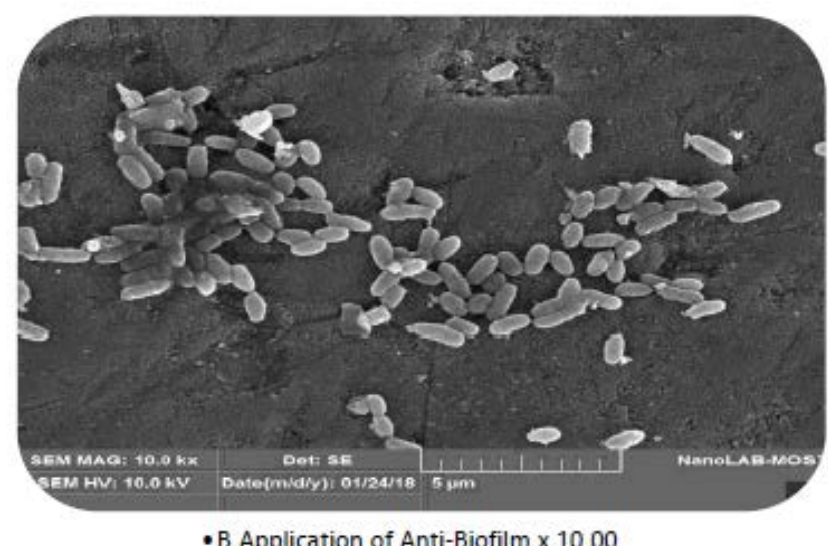

-B.Application of Anti-Biofilm x 10.00

Figure 1. Application of Biofilm and Anti-Biofilm on Streptococcus mutans on Permanent Tooth 

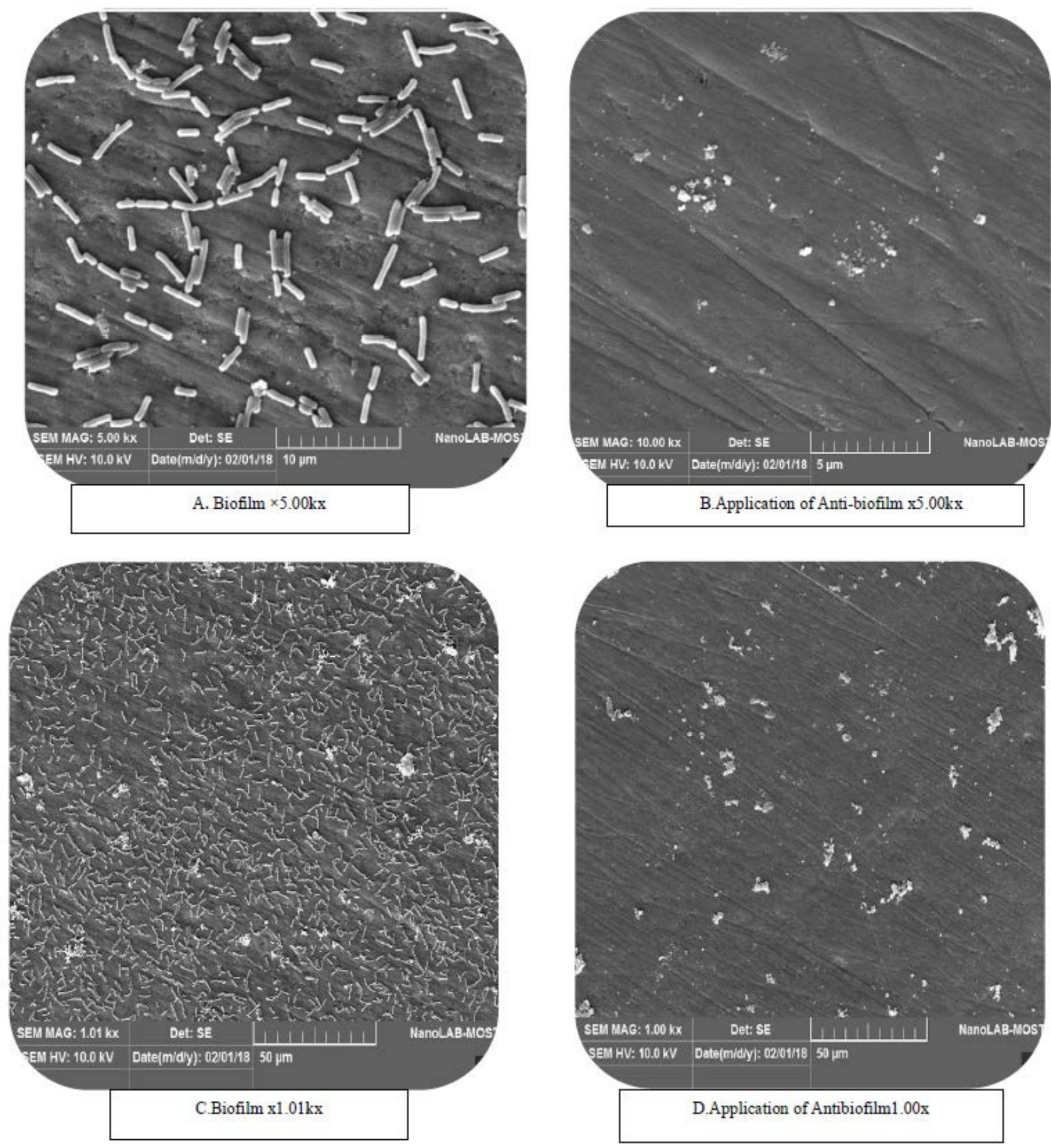

Figure 2.:Biofilms and Application of Antibiofilms of Facklamia hominis and Streptococcus salivarius on Deciduous Teeth surfaces

As it was observed using SEM, dramatic decline in formed biofilms of the three tested strains was observed on the four tested surfaces after the application of tooth paste contained $0.45 \%$ for 30 min (Figure 2 Figure 5). The decline included both bacterial cells and exopolysacchaides.

In relation to the two natural surfaces, the tested tooth paste inhibited the formed biofilms efficiently in the same manner. This may be explained by two factors; similar enamel topography and similar plaque bacterial species composition of permanent and deciduous teeth.

Although microstructures and mineral compositions of dental enamel was different between permanent teeth and deciduous teeth, enamel rods density was higher in the deciduous teeth and the percentage of calcium and phosphorus was higher in the permanent teeth enamel [22,23,24]. Maria Ange et al, 2010 concluded that the morphological analysis of the enamel rod diameter in deciduous teeth was statistically similar to that of permanent teeth enamel. [11]

Microbiologically, although different bacteria can attach to solid surfaces with different strengths, there was no statistically significant difference of bacterial species composition isolated from supragingival plaques with deciduous and permanent teeth $[25,26]$.

In relation to the two artificial surfaces, the tested tooth paste inhibited the formed biofilms more efficiently on composite than amalgam filling surfaces. This can be explained by differences in material roughness and composition. 
The composite filling material used in this study was Estelite alpha, Tokuyama, Japan. The producer claimed to provide high gloss with little polishing. In Figure 3 and Figure 4, even the polishing process was done with the same manner ,composite surface appeared more smooth and gloosy than amalgam surfaces which had rough and cracked appearances.

Microbial adhesion on filling material surfaces(which is important step of biofilm formation) depends on the surface topography, chemical composition of these materials, and on the physicochemical properties of the bacterial cell surface(its surface charge and hydrophobicity) [27,28].

\section{1-Roughness of Dental Material Surfaces}

Bacterial initial attachment on roughened surfaces is aided by surface irregularities, where bacteria are protected from salivary flow(in this study, bacteria were protected from washing with PBS) so,bacteria can attach to pits and grooves in a way that reduce the influence of

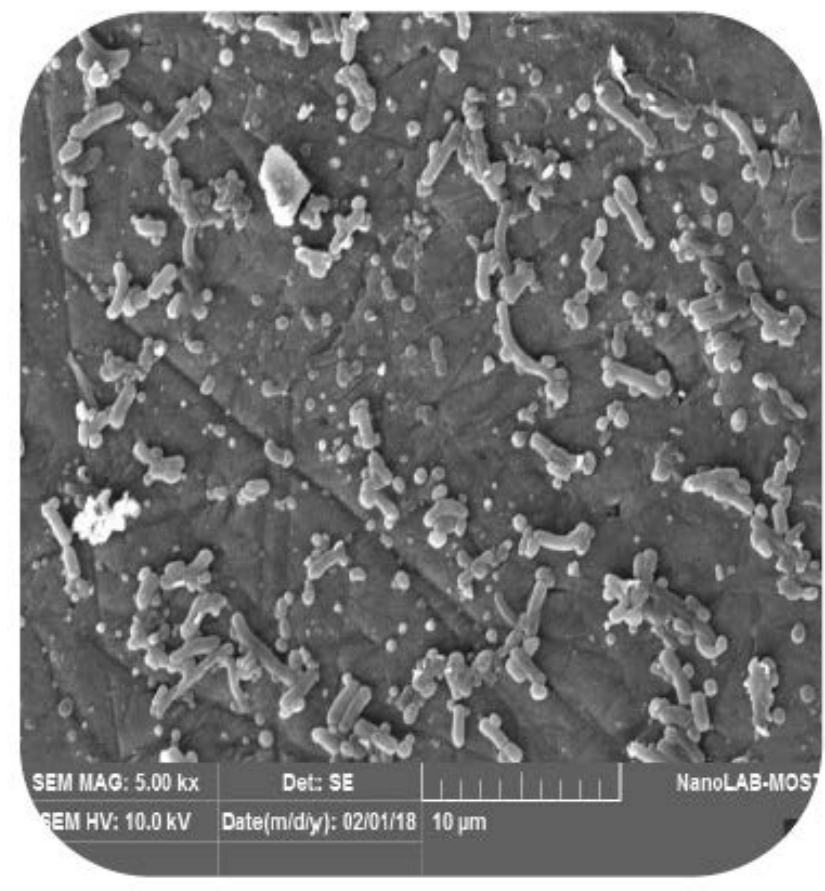

A.Biofilm $\times 5.00$

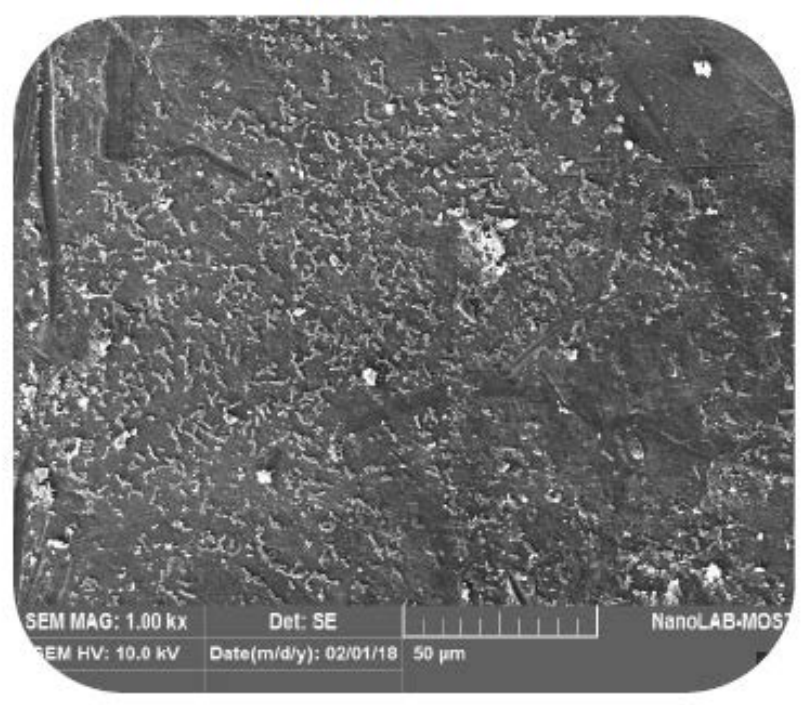

C.Biofilm $\times 1.00$ shear forces on them [29,30].

Einwag et al. 1990 examined the influence of the surface roughness of dental filling materials on plaque accumulation and found that $S$. mutans adhered more efficiently to rough surfaces than to high polished filling materials. [31] This approach agreed by Mei et al. 2011 who evaluated the streptococcal adhesion forces with composite resins with different surface roughness. They confirmed that adhesion forces of streptococcal bacteria to composite resin materials increase directly with increasing roughness of its surfaces [32].

However, some researchs were some-what confused. Yamauchi et al. 1990 stated that the influence of surface roughness was strain dependent. They founded that some strains (S. oralis, $P$. intermedia, and $P$. gingivalis) were higher in amounts on rough surfaces, whereas others (S. sanguis, S. mutans, S. mitis and P. gingivalis) were higher in amounts on smooth surfaces. [33]

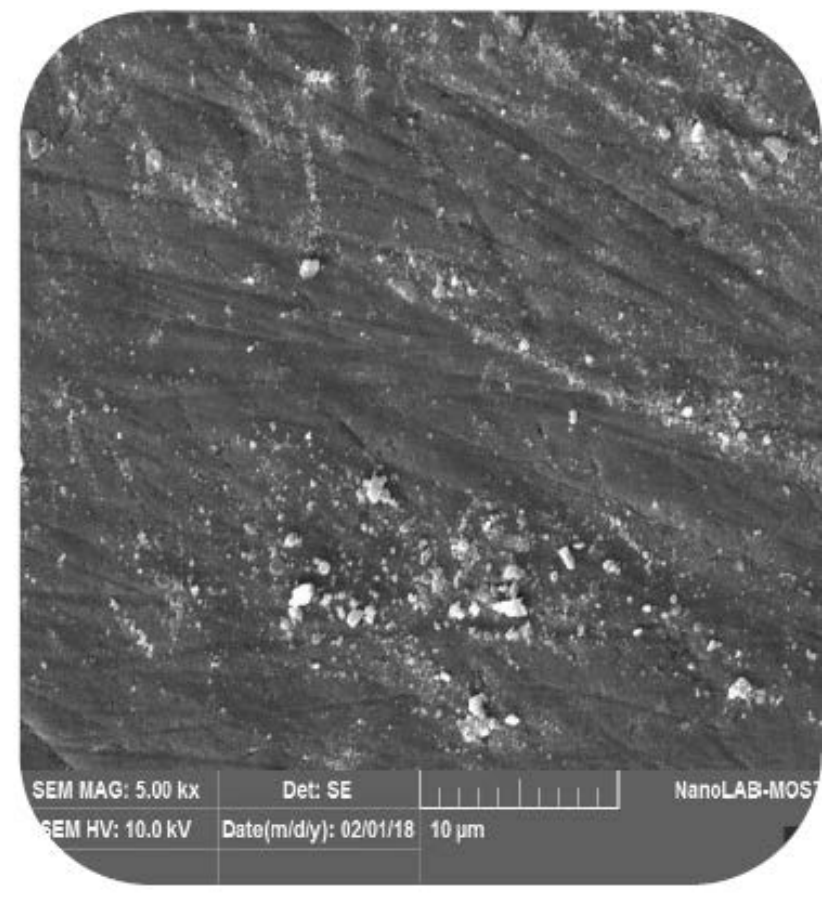

B.Application of Anti-biofilm x 5.00

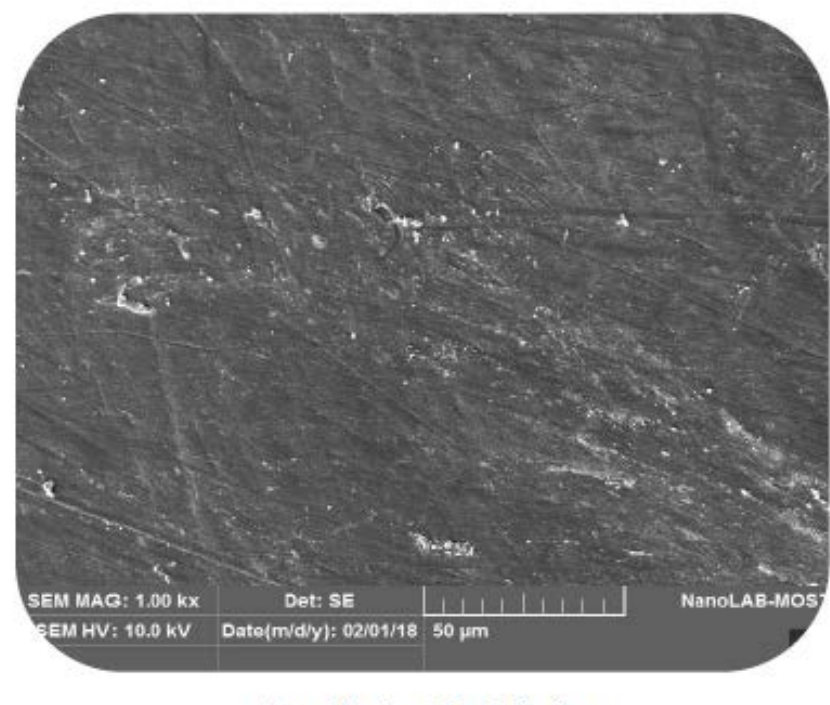

D. application of Anti-Biofilm

Figure 3. Biofilms and Application of Antibiofilms of Fakclamia hominis and Streptococcus salivarius on Permanent Teeth surfaces 


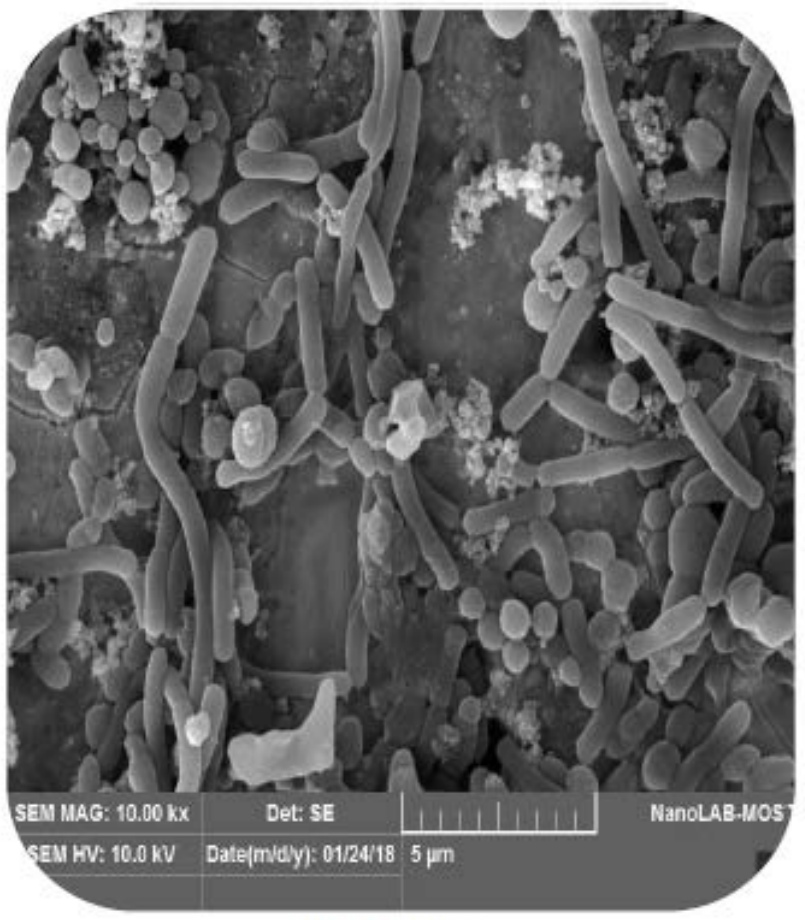

A.Biofilm $x 10.00$

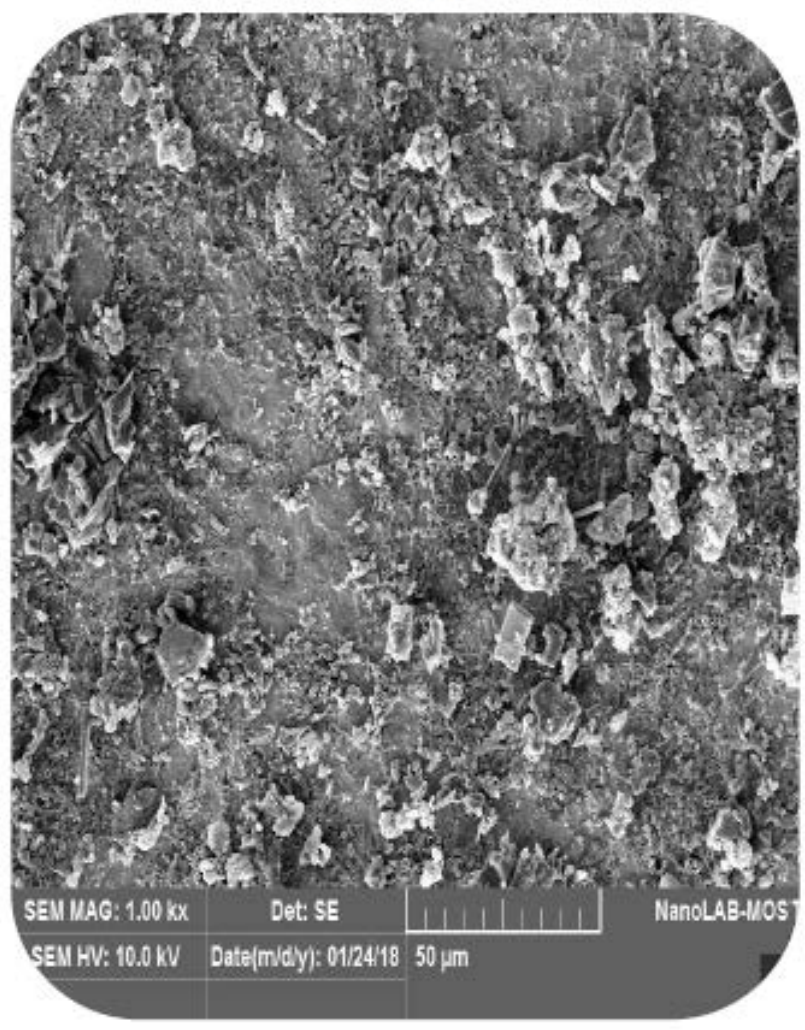

C. Biofilm $x 1.00$

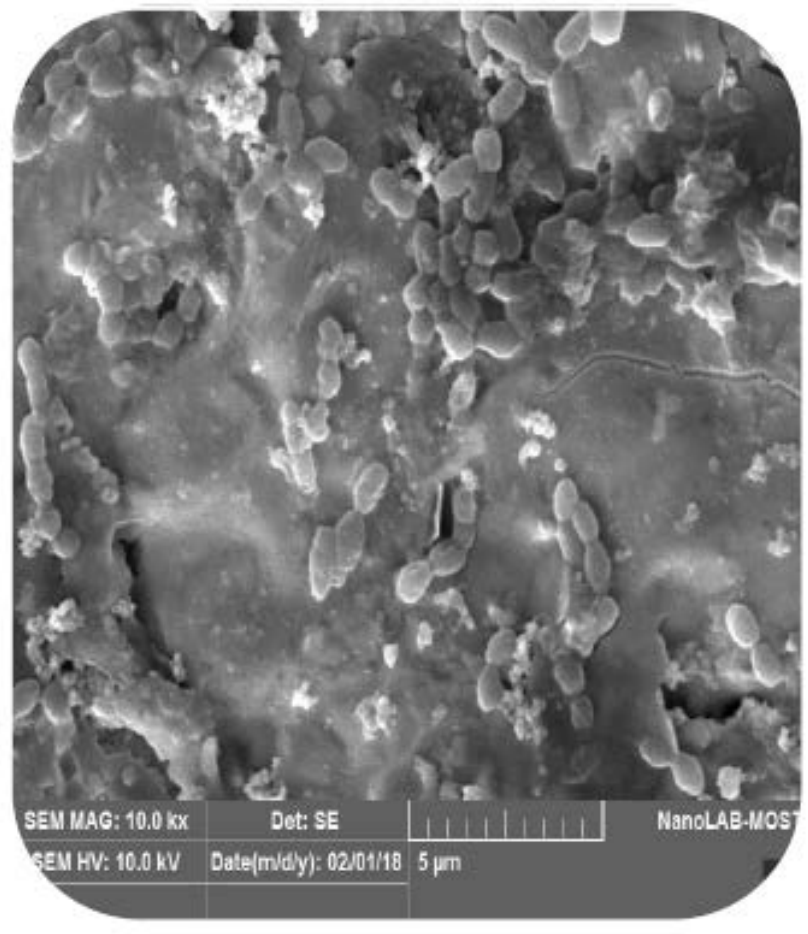

B.Application of Anti- Biofilm x10.00

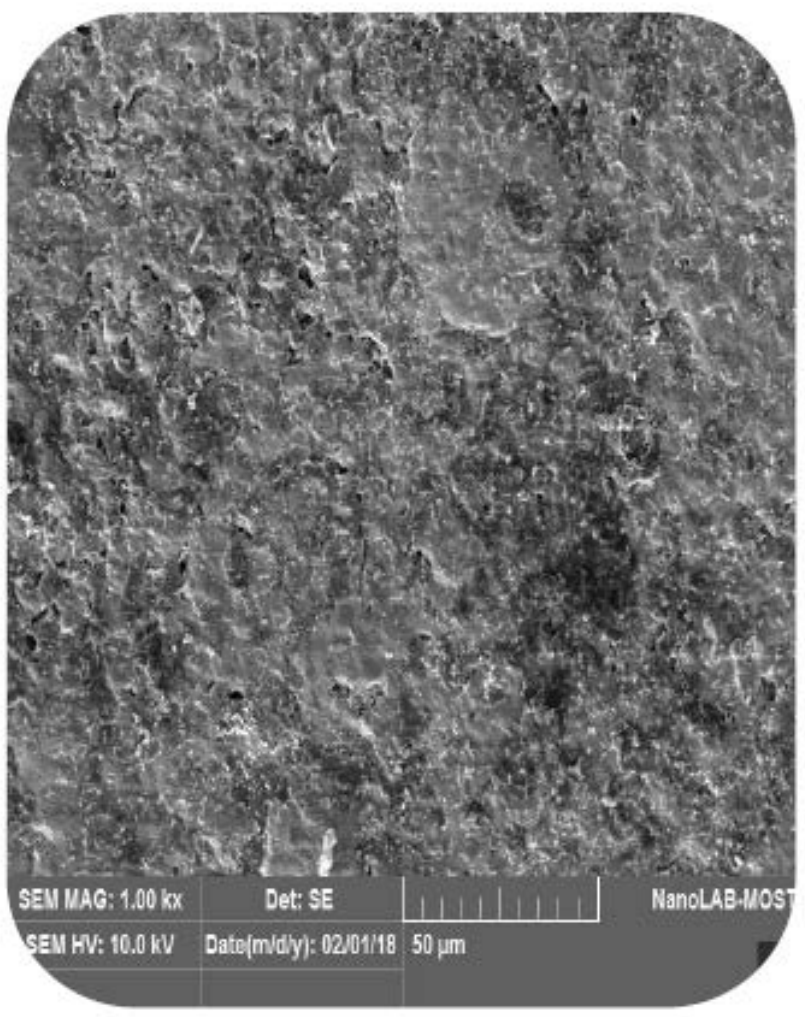

D.Application of Anti-Biofilm x1.00

Figure 4. Biofilms and Application of Antibiofilms of Facklamia hominis and Streptococcus mutans on Amalgam surfaces

\section{Hydrophobicity and Surface Charge}

Bacterial colonization to a specific surface is determined by surface characteristics such as its hydrophobicity and surface charge. [34]

Bacterial cells, which have hydrophobic cell surfaces, can be attracted to many materials surfaces leads to increased adherence and subsequent biofilm formation. [35] A decrease in the surface hydrophilicity of any material can lead to strong hydrophobic interaction between infective bacteria and the filling material and then increase adherence [36].

The bacterial cell wall have many structures and properties that aid in bacterial adhesion (teichoic acid in gram-positive bacteria). These characteristics influence the surface charge and hydrophobicity of the bacterial cell, thereby directly affecting adherence. [37] 


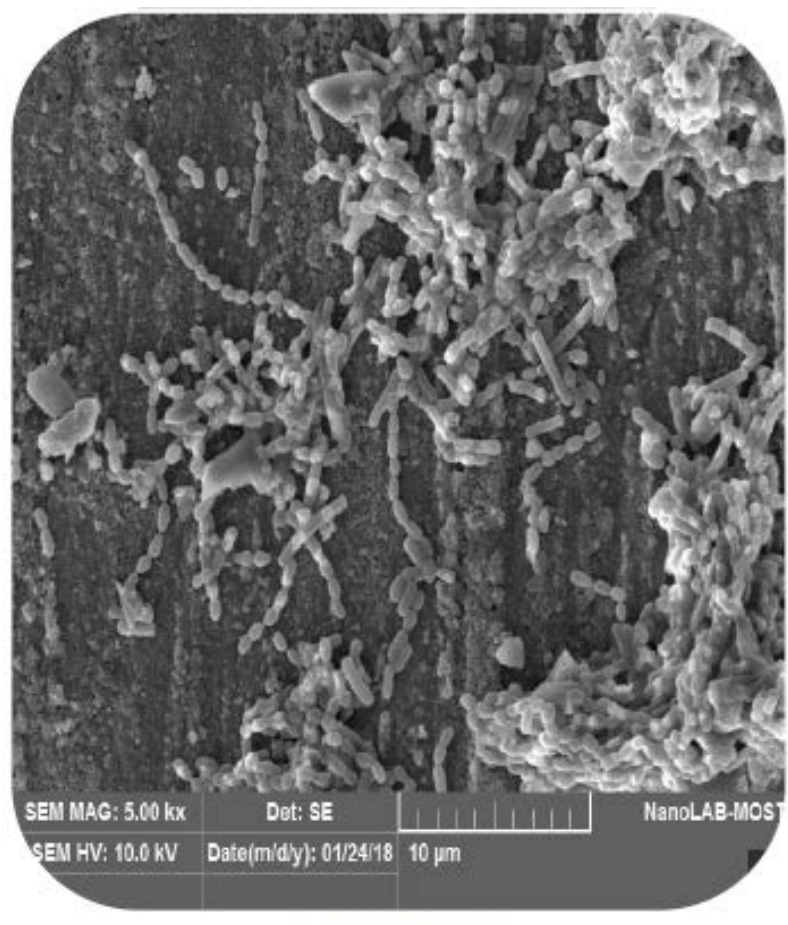

A.Biofilm $\times 5.00$

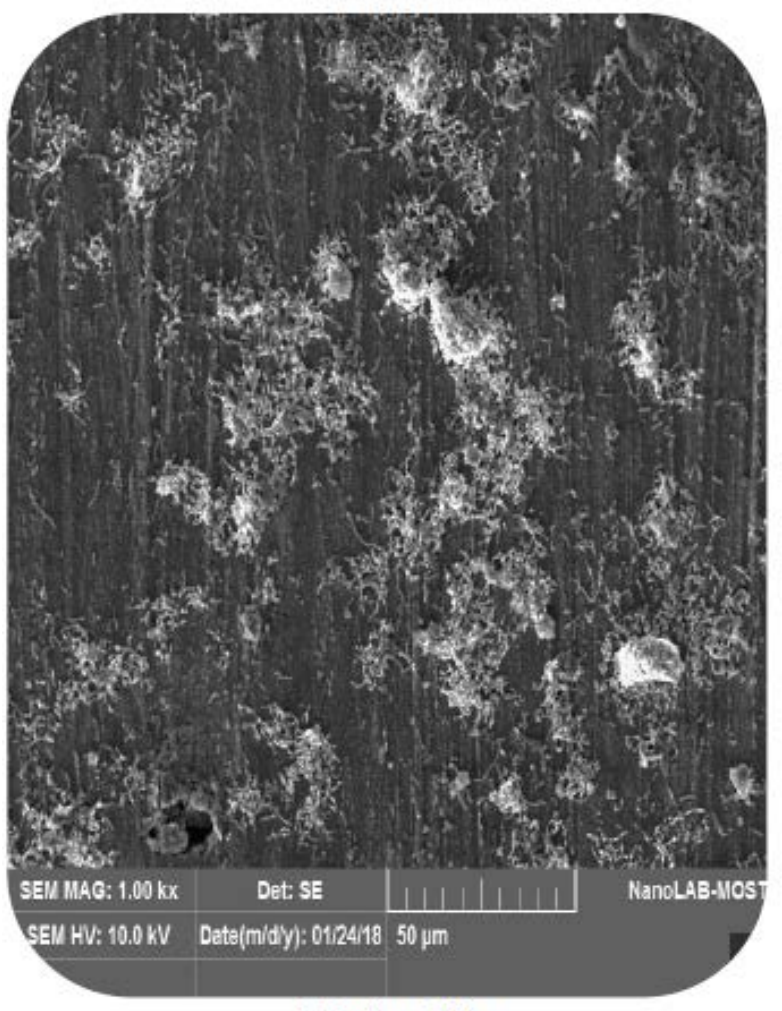

C.Biofilm $x 1.00$

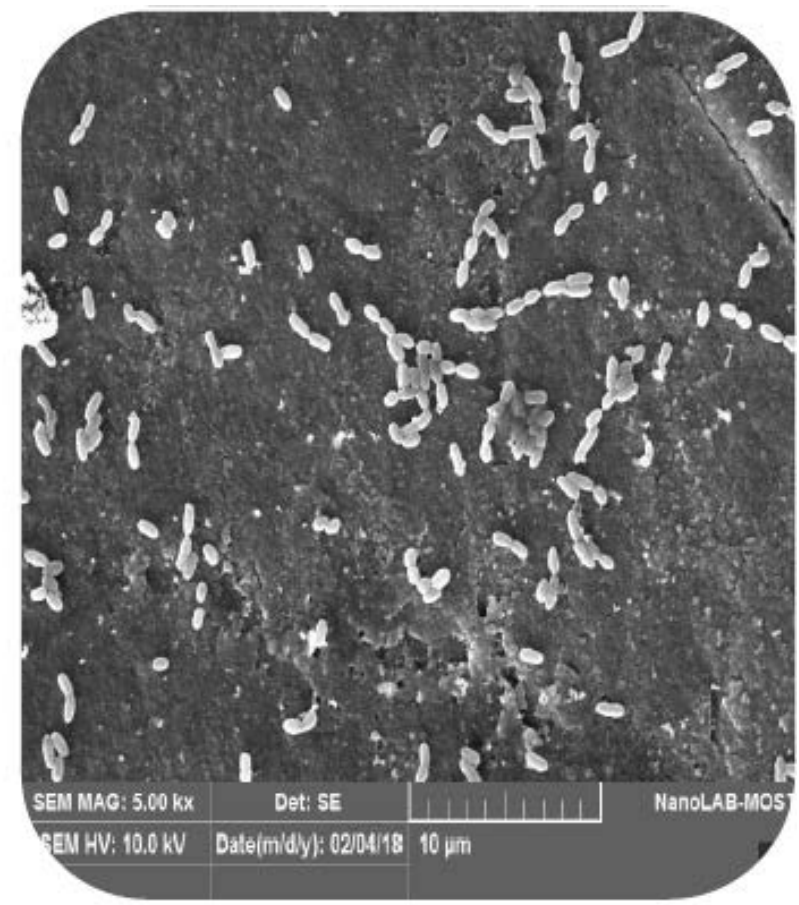

B.Application of Anti-Biofilm x 5.00

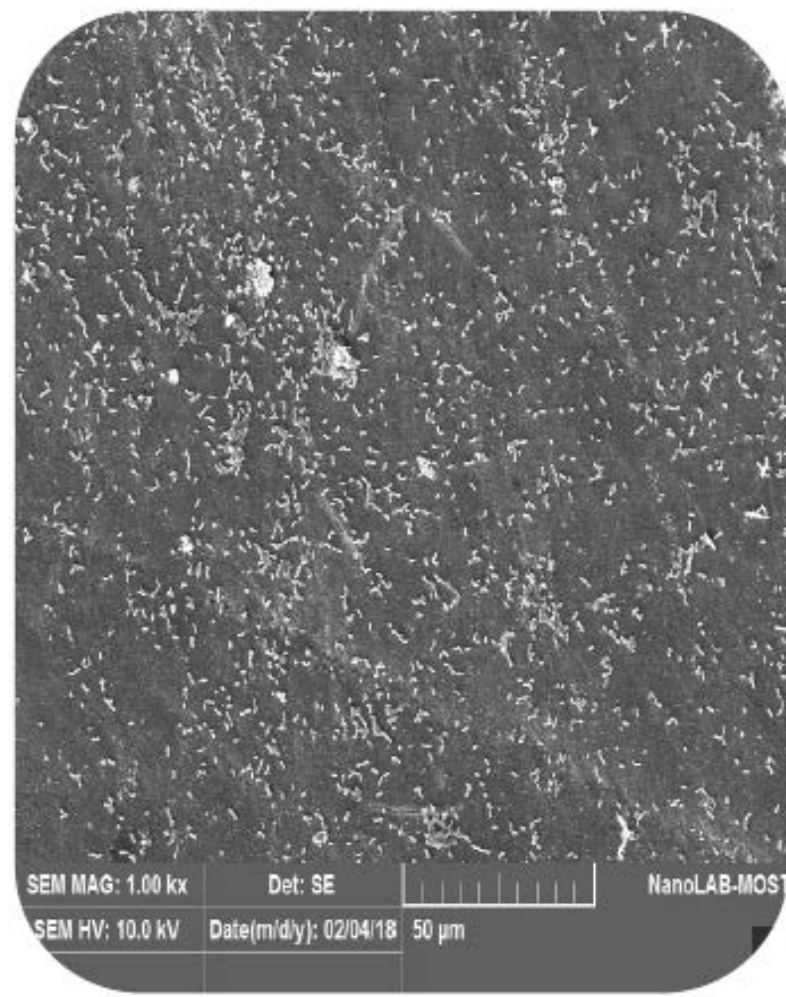

D.Application of Anti-Biofilm x1.00

Figure 5. Biofilms and Application of Antibiofilms of Facklamia hominis and Streptococcus mutans on Composite surfaces

Filling material surface charge greatly influences bacterial adherence. Most bacteria exhibit a negative surface charge in an aqueous environment. Therefore, a negatively charged filling material surface should lead to decreased adherence of microorganisms due to a repulsion effect between both negatively charged surfaces [38].

In conducting materials, like amalgam, electron-transfer plays an important role in bacterial adhesion. [39] This can be due to attractive forces between the negatively charged bacteria and positive charges in the conducting material. This cannot occur in a non-conducting material (e,g, resin composite) [40].

\section{Anti-bacterial Effects of Dental Materials}

A. Leonhardtt, et al 1995 proposed that the different kinds of materials may not have any antibacterial properties in vivo, and the colonizing bacteria has a similar composition regardless of material type [41].

This opinion was refused by another school who claimed that dental materials have different effects on bacteria. Several studies have shown that amalgam alloys 
have a bacteriostatic effect $[42,43,44]$. However, it is possible that bacteria develop resistance against mercury (which is part of dental amalgam). In vitro, more bacteria resistant to mercury were found in oral biofilms grown on amalgam than on enamel. [41] According to study that performed by Ready et al 2007, 98\% of mercury resistant bacterial strains isolated, were streptococci [45].

Opposite to our study, Bernardo et al 2007, proposed that certain component of resin (methacrylate polymers) encourages the growth of microorganisms. [44] Hansel et al 1998 suggested that the release of ethyleneglycol dimethylacrylate and triethyleneglycol dimethacrylate from composite resins may enhance the growth of mutans streptococci and lactobacilli which were found mostly along the margins of composite fillings [45].

\section{Conclusions}

The focus of the current study was antibiofilm activity which represents an important outcome of good oral hygiene control. It may be particularly advantageous when mechanical oral hygiene measures are not enough. Results from this study have proved that flourdated toothpaste formulation remains a gold standard as far as antimicrobial efficacy is concerned. This paste can remove the biofilms associated with the bacteria of dental caries so, it can prevent primary caries on permanent and deciduous tooth surfaces. Notably, it can also prevent secondary caries on composite filling material surfaces and to lesser extent on amalgam surfaces.

\section{References}

[1] Lamont, R.J. Oral Microbiology and Immunology; ASM Press: Washington, DC, USA, 2006.

[2] Marit Øilo and Vidar Bakken. Biofilm and Dental Biomaterials, Materials 2015, 8, 2887-2900.

[3] Beighton D: The complex oral microflora ofhigh-risk individuals and groups and its role in the caries process. Community Dent Oral Epidemiol 2005; 33: 248-255

[4] R. J. Fitzgerald and P. H. Keyes, "Demonstration of the etiologic role of streptococci in experimental caries in the hamster," The Journal of the American Dental Association, 1960, vol. 61, pp. 9-19.

[5] Kolenbrander PE, Palmer RJ Jr, Periasamy S, Jakubovics NS.Oral multispecies biofilm development and the key role of cell-cell distance. Nat Rev Microbiol. 2010; 8: 471-80

[6] Gamboa F, Estupinan M, Galindo A. Presence of Streptococcus mutans in saliva and its relationship with dental caries: Antimicrobial susceptibility of the isolates. Universitas Scientiarum. 2004; 9(2): 23-7.

[7] Regos J, Hitz HR. Investigations on the mode of action of triclosan, a broad-spectrum antimicrobial agent. Zentbl. Bakteriol. Parasitenkd. Infektkrankh. Hyg. Abt. 1 Orig. Reihe A 1974; 226: 390-401.

[8] Degiam Z.D., An in Vitro Antimicrobial activity of six commercial toothpastes, This-qar. Med. J. (TQMJ), 2010, 4(4), 127-133.

[9] Marinho V, Higgins J, Logan S, Sheiham A. Fluoride toothpastes for preventing dental caries in children and adolescents. Cochrane Database of Systematic Reviews 2003; Issue 1.

[10] Australian Government, National Health and Medical Research Council. A Systematic Review of the Efficacy and Safety of Fluoridation, 2007.

[11] Maria Ange' Lica Hubb DeMenezes Oliveria.Carolina Paestorres, Jaciaramiranda Gomes-Silva, Michelle Alexandra Chinelatti, Fernando Carlos Hueb De Menezes, Regina Gueika Palma-Dibb and Maria Cristina Borsaatto,Microstructure and Mineral Composition of Dental Enamel of Permanent and Deciduous Teeth microscopy research and technique 2010, 73:572-577.

[12] Gavin, P. J., J. R. Warren, A. A. Obias, S. M. Collins, and L. R. Peterson. 2002. Evaluation of the Vitek 2 system for rapid identification of clinical isolates of gram-negative bacilli and members of the family streptococcaceae. Eur. J. Clin. Microbiol. Infect. Dis. 21: 869-874.

[13] Hope CK, Burnside G, Chan SN, Giles LH, Jarad FD. Validation of an extracted tooth model of endodontic irrigation. J Microbiol Methods 2011; 84: 131-3.

[14] Abd El-Bakey R.M. Application of Scan Electron Microscope for the Morphological Study Of Biofilm in Medical Devices, Microbiology Department ,Faculty of Pharmacy, Minia University, Egypt; 201230: 591-616.

[15] Clinical and laboratory standards institutes. Performance standard for antimicrobial susceptibility testing,Seventeenth informational supp. 2007, M100-S17, PA).

[16] Addy M. Chemical plaque control. In: Kieser BJ, editor. Periodontics: a practical approach. London: Wright Publishing Company; 1990. pp. 527-34.

[17] Menendez A, Li F, Michalek SM, Kirk K, Makhija SK, Childers NK. Comparative analysis of the antibacterial effects of combined mouthrinses on Streptococcus mutans. Oral Microbiol Immunol. 2005; 20(1): 31-4

[18] Sanz M. Serrano J. Iniesta M. Santa Cruz I. Herrera D. Antiplaque and Antigingivitis Toothpastes Karger, 2013, vol 23, pp 27-44.

[19] Buzalaf MA, Pessan JP, Honório HM, ten Cate JM. Mechanisms of action of fluoride for caries control. Monogr Oral Sci 2011; 22: 97-114.

[20] Bradshaw DJ, Marsh PD, Hodgson RJ, Visser JM. Effects of glucose and fluoride on competition and metabolism within in vitro dental bacterial communities and biofilms.2002 Caries research 36: 81-86.

[21] P.S. Watson, H.A. Pontefract, D.A. Devine1, R.C. Shore, B.R. Nattress, J. Kirkhamand C. Robinson. Penetration of Fluoride into Natural Plaque Biofilms J Dent Res 2005, 84(5): 451-455.

[22] Bath-Balogh M, Fehrenbach MJ, Thomas P, Cmi. Illustrated Dental Embryology, Histology, And Anatomy. Saunders. 1997; 23(2): 44

[23] Scheid RC, Woelfel JB. Woelfel's dental anatomy: its relevance to dentistry. Wolters Kluwer/Lippincott Williams \& Wilkins. 2007.

[24] De Menezes Oliveira MA, Torres CP, Gomes-Silva JM, Chinelatti MA, De Menezes FC, Palma-DibbRG, et al. Microstructure and mineral composition of dental enamel of permanent and deciduous teeth. Microscopy research and technique. 2010; 73(5): 572-7.

[25] J. Olossn and B. Krasse. Method for studying adherence of oral streptococci to solid surfaces, European Journal of Oral Sciences1976, Vol 84, issue 2p. 20-28.

[26] Rokiewicz D, Daniluk T , Zaremba ML, Cylwik-Rokicka D, Łuczaj-Cepowicz E, Milewska R, Marczuk-Kolada G, Stokowska W Bacterial composition in the supragingival plaques of children with and without dental caries. Advances in Medical Sciences. 2006. Vol. 51. Suppl. 1.

[27] M. N. Bellon-Fontaine, N. Mozes, H. C. van der Mei, J. Sjollema, O. Cerf, P. G. Rouxhet and H. J. Busscher, "A Comparison of Thermodynamic Approaches to Predict the Adhesion of Dairy Microorganisms to Solid Sub-strata," Cell Biophysics, Vol. 17, No. 1, 1990, pp. 93-106.

[28] H. J. Busscher, M. M. Cowan and H. C. van der Mei, "On the Relative Importance of Specific and Non-Specific Approaches to Oral Microbial Adhesion,” FEMS Micro-biology Reviews, Vol. 8, No. 3-4, 1992, pp. 199-209.

[29] Y. H. An and R. J. Friedman, "Concise review of mechanisms of bacterial adhesion to biomaterial surfaces," Journal of Biomedical Materials Research, vol. 43, no. 3, pp. 338-348, 1998.

[30] B. Nyvad and O. Fejerskov, "Scanning electron microscopy of early microbial colonization of human enamel and root surfaces in vivo,” Scandinavian Journal of Dental Research, vol. 95, no. 4,pp. 287-296, 1987.

[31] J. Einwag, A.Ulrich and F. Gehring, "In-Vitro Plaque Accumulation on Different Filling Materials," Oralprophylaxe, Vol. 12, No. 1, 1990, pp. 22-25.

[32] L. Mei, H. J. Busscher, H. C. van der Mei and Y. Ren, "Influence of Surface Roughness on Streptococcal Adhe-sion Forces to Composite Resins,” Dental Materials, Vol. 27, No. 8, 2011, pp. 770-778. 
[33] M. Yamauchi, K. Yamamoto, M. Wakabayashi and J. Kawano, "In Vitro Adherence of Microorganisms to Den-ture Base Resin with Different Surface Texture,” Dental Materials Journal, Vol. 9, No. 1, 1990, pp. 19-24.

[34] R. D. Fields and M. V. Lancaster, "Dual-attribute continuous monitoring of cell proliferation/cytotoxicity," American Biotechnology Laboratory, vol. 11, no. 4, pp. 48-50, 1993.

[35] Schierholz, J.M and Beuth, J.. Implant infections: a haven of opportunistic bacteria. J. Hosp. Infect., 2001 49: 87-93.

[36] John L.Pace,Mark E.Rupp and Roger G. Finch. (2005). Biofilm, Infection and Antimicrobial Therapy, Taylor and Franks Group; 43-45.

[37] Bonner, M.C.; Tunney, M.M.; Jones, D.S. and Gorman, S.P. Factors affecting in-vitro adherence of ureteral stent biofilm isolates to polyurethane. Int. J. Pharmaceutics. 1997, 151: 201-207.

[38] Jansen, B.; Peters, G. and Pulverer, G.. Mechanisms and clinical relevance of bacterial adhesion to polymers. J. Biomatr. Appl.1988, 2: 520-543.

[39] A. T. Poortinga, R. Bos and H. J. Busscher, "Measure-ment of Charge Transfer during Bacterial Adhesion to an Indium Tin Oxide Surface in a Parallel Plate Flow Cham-ber," Journal of Microbiological Methods, Vol. 38, No. 3, 1999.
[40] L. Mei, H. C. Van der Mei, Y. Ren, W. Norde and H. J. Busscher, "Poisson Analysis of Streptococcal Bond Strengthening on Stainless Steel with and without a Sali-vary Conditioning Film,” Langmuir, Vol. 25, No. 11, 2009, pp. 6227-6231.

[41] A. Leonhardtt, J. Olsson2, and G. Dahlen. Bacterial Colonization on Titanium, Hydroxyapatite, and Amalgam Surfaces in vivoJ Dent Res 1995, 74(9): 1607-1612.

[42] Glassman MD, Miller IJ. Antibacterial properties of one conventional and three high-copper dental amalgams. J Prosthet Dent 1984, 52: 199-20350-51

[43] D. Ready, J. Pratten, N. Mordan, E. Watts and M. Wilson, "The Effect of Amalgam Exposure on Mercury- and An-tibioticResistant Bacteria," International Journal of An-timicrobial Agents, Vol. 30, No. 1, 2007, pp. 34-39.

[44] Bernardo, M; Martin, MD; Lerouz, BG. "Survival and reasons for failure of amalgam versus resin-based composites posterior restorations placed in a randomized clinical trial". The Journal of the American Dental Association. 2007, 138: 775-78.

[45] C. Hansel, G. Leyhausen, U. E. Mai and W. Geurtsen, "Effects of Various Resin Composite (Co)monomers and Extracts on Two Caries-Associated Micro-Organisms in Vitro,” Journal of Dental Research, Vol. 77, No. 1, 1998, pp. 60-76. 